\title{
Chronic Diseases, Depressive Symptoms and Socio-economic Characteristics Among Older Adults in Morocco: A pilot Study on Gender Differences
}

\author{
(D) Abdelhafid Benksim1,2, (D) Rachid Ait-Addi1, (D) Elhassania Khalloufi1,2, (D) Aziz Habibi1, (D) Mohamed Amine3, \\ (D) Mohamed Cherkaoui1 \\ 1 Laboratory of Human Ecology, Faculty of Sciences Semlalia, Marrakesh, Morocco \\ 2 Higher Institute of Nursing Professions and Health Techniques, Marrakesh, Morocco \\ ${ }^{3}$ Epidemiology Laboratory, Faculty of Medicine and Pharmacy, Marrakesh, Morocco
}

\begin{abstract}
Objective: Nowadays, the burden of chronic diseases and functional disabilities in elderly people has increased considerably in Morocco. Was to examine gender differences in self-reported health of the elderly, taking into account socio-economic, demographic and family characteristics.
\end{abstract}

Materials and Methods: A cross-sectional survey was conducted in Marrakech province. A group of 368 individuals aged 60 years or older was selected by a non-probability sampling through face-to-face interviews between March 2017 and June 2018. All participants were recruited from four community health care centers in the districts of Massira, Mhamid, and Daouidiate in Marrakech province. Statistical analyses were performed using SPSS software-version 16.0 (SPSS Inc., Chicago, IL, USA).

Results: Most elderly had poor socio-economic and health status with women being the most disadvantaged. Elderly women were significantly less educated, had no partner and were financially dependent on their children and relatives. They continued to suffer from depressive symptoms, musculoskeletal and gastrointestinal diseases $(p<0.05)$. According to multivariate logistic regression analysis, marital status [odds ratio $(O R)=0.257: 0.140-0.472)]$, occupational status $(O R=0.242: 0.152-0.384)$ and number of children (OR=0.399:0.212-0.753), musculoskeletal diseases $(\mathrm{OR}=2.446: 1.372-4.359)$ and gastrointestinal diseases $(\mathrm{OR}=2.856: 1.392-5.862)$ were relatively independent predictive variables in elderly women.

Conclusion: This gender study explored the socio-economic, nutritional, well-being and psychological status of elderly residents in Morocco. These outcomes indicated the need for health support and institutional involvement for older people with more attention to the well-being of women.

Keywords: Aged, chronic disease, depression, gender identity, Morocco

\section{Introduction}

Population aging is considered as serious problem of health and social welfare challenges for all countries in the world (1). The world's population aged 60 and over will today increase from more than 800 million to two billion by 2050 (2). Prior studies have confirmed that gender differences are generally related to socio-economic and demographic characteristics which contribute to health inequalities in older people (3-5). Although women have a longer life expectancy than men (1); they are more likely to suffer from arthritis, osteoporosis, diabetes, hypertension, physical limitations and multiple chronic diseases which largely make them more dependent on their daily lives (4).

The main objective of this study was to determine the differences in health state among elderly men and women, using a combined framework of socio-economic status and functional impairments.

Address for Correspondence: Abdelhafid Benksim, Laboratory of Human Ecology, Faculty of Sciences Semlalia, Marrakesh, Morocco Phone: +90 212661197370 E-mail: benksima@gmail.com ORCID: orcid.org/0000-0002-2470-3718

Received: 28 Jan, 2020 Accepted: 10 Apr, 2020

Cite this article as: Benskim A, Ait-Addi R, Khalloufi E, Habibi A, Amine M, Cherkaoui M. Chronic Diseases, Depressive Symptoms and Socio-economic Characteristics Among Older Adults in Morocco: A pilot Study on Gender Differences. Eur J Geriatr Gerontol 2020;2(1):18-23

${ }^{\circ}$ Copyright 2020 by the Academic Geriatrics Society / European Journal of Geriatrics and Gerontology published by Galenos Publishing House. 


\section{Materials and Methods}

A cross-sectional study was conducted with the approval of the Ethic of the Moroccan health authorities in the region of Marrakech-Safi. A group of 368 older persons aged 60 years and over were selected by a non-probability sampling between March 2017 and June 2018. All participants were selected anonymously and privately through a face-to-face interview. According to the declaration of Helsinki, the study protocol was explained and informed consent was obtained. This declaration includes the fact that participants voluntarily agree to participate after being fully informed of the purpose, methods, risks, and benefits of our study via verbal discussion with study staff, followed by documentation in a written and signed informed consent form.

An interview guide was developed based on the study framework to guarantee that the same questions would be asked of each interviewed participant. This questionnaire includes a list of items relating to socio-economic and demographic characteristics (such as age, sex, marital status, number of children, educational level, previous employment status, income and the degree of perceived family support etc.).

In our survey, a nutritional mini-evaluation-short form (MNA$\mathrm{SF}$ ) is used to measure nutritional status (ranging from 0 to 14) (6). This tool includes six questions relating to anthropometric measurements, global assessment (mobility), dietary questionnaire and subjective assessment (neuropsychological problems, food intake). The MNA-SF scale is interpreted as follows: 1) Malnutrition: Zero to seven points, 2) Risk of malnutrition: Eight to 11 points and 3) Normal: Twelve points or greater.

Furthermore, searching health booklets provided all clinical and nutritional information such as functional disabilities and chronic diseases. Hence, the degree of physical disabilities was assessed when a person performed basic activities of daily living. There are six basic activities of daily living including bathing, dressing, feeding, transferring, continence and toileting (7).

In this survey, depressive symptoms were assessed with the 15item version of the Geriatric Depression scale (GDS-SF), ranging from zero to 15 points: 1) Normal: Zero-five, 2) Moderate depression: Six-ten and 3) Severe depression: 11-15 (8). This scale is a screening tool for depression in the elderly in 15 questions, usually filled between five to seven minutes. Exclusion criteria were participants with dementia, severe neuropsychological disorders and speech impairments.

\section{Statistics}

All data were entered into database and analysed using SPSS software (version 16.0, Chicago, IL, USA). Pearson's $\chi^{2}$ test and Fisher's exact test were used for differences in the percentage of nominal variables. Student's t-test was used to compare the means of variable. In order to explore gender differences, a multivariate analysis was performed to eliminate the confounders. A p-value less than 0.05 , was regarded as statistically significant.

\section{Results}

A total of 368 participants were successfully included in this study. The socio-economic levels and demographic characteristics are given in Table 1. Of those interviewed, $45.9 \%$ were men and $54.1 \%$ were women. Moreover, $52.4 \%$ of participants are living in urban areas, $65 \%$ are widowed, and $83 \%$ are illiterates. Besides, older women complain significantly about illiteracy $(78.9 \%)$, widowhood $(66.8 \%)$, lack of health insurance (81.9\%), and low income in the past (79.9\%) than men counterparts $(p \leq 0.005)$. The analysis of family characteristics showed that the older women continue to keep up a good relationship with their children (77.88\%). Nevertheless, the clinical information and self-reported morbidities are presented in Table 2. The musculoskeletal disorders (38.7\%), cardiovascular diseases (37.7\%) and the gastrointestinal diseases (24.6\%) were significantly the most common morbidities in older women $(p<0.05)$. In addition, edentulism, visual, metabolic, kidney and respiratory diseases are gradually identified in elderly men and women without significant differences $(p>0.05)$. Besides, there were statistically no significant differences between the elderly women and men on malnutrition status ( $p=0.364)$.

\begin{tabular}{|c|c|c|c|}
\hline Variables and modalities & $\begin{array}{l}\text { Older men } \\
(\%)\end{array}$ & $\begin{array}{l}\text { Older women } \\
(\%)\end{array}$ & $\mathbf{p}$ \\
\hline Age (year) & $69.1 \pm 5.2$ & $68.8 \pm 8.91$ & 0.151 \\
\hline $\begin{array}{l}\text { Current marital status } \\
\text { Without partner } \\
\text { With partner }\end{array}$ & $\begin{array}{l}71(42.0) \\
98(58.0)\end{array}$ & $\begin{array}{l}133(66.8) \\
66(33.2) \\
\end{array}$ & 0.001 \\
\hline $\begin{array}{l}\text { Education level } \\
\text { Illiterate } \\
\text { Primary school } \\
\text { High school and above }\end{array}$ & $\begin{array}{l}115(68.0) \\
29(17.2) \\
25(14.8)\end{array}$ & $\begin{array}{l}157(78.9) \\
28(14.1) \\
14(7.0)\end{array}$ & 0.027 \\
\hline Health insurance & $41(24.3)$ & $36(18.1)$ & 0.147 \\
\hline $\begin{array}{l}\text { Previous occupation levels } \\
\text { Low-income (1) } \\
\text { With Middle-income (2) } \\
\text { With high-income (3) }\end{array}$ & $\begin{array}{l}68(40.2) \\
82(48.5 \\
19(11.2) \\
\end{array}$ & $\begin{array}{l}159(79.9) \\
28(14.1) \\
12(6.0) \\
\end{array}$ & 0.001 \\
\hline $\begin{array}{l}\text { Origin } \\
\text { Urban } \\
\text { Rural }\end{array}$ & $\begin{array}{l}86(50.9) \\
83(49.1) \\
\end{array}$ & $\begin{array}{l}99(49.7) \\
100(50.3) \\
\end{array}$ & 0.828 \\
\hline $\begin{array}{l}\text { Number of children } \\
1 \text { or more } \\
0\end{array}$ & $\begin{array}{l}111(65.7) \\
58(34.3)\end{array}$ & $\begin{array}{l}149(74.87) \\
50(25.12) \\
\end{array}$ & 0.040 \\
\hline $\begin{array}{l}\text { Relationship with children } \\
\text { Good relationship } \\
\text { Mediocre relationship }\end{array}$ & $\begin{array}{l}116 \text { (68.63) } \\
37(31.36)\end{array}$ & $\begin{array}{l}155(77.88) \\
36(22.12)\end{array}$ & 0.209 \\
\hline
\end{tabular}


Furthermore, to screen the depressive symptoms, the GDF-SF: short form was performed. We found that severe depression was significantly observed among elderly women compared to men counterparts $(p=0.030)$.

\begin{tabular}{|c|c|c|c|}
\hline Variables and modalities & Older men (\%) & Older women (\%) & $\mathbf{p}$ \\
\hline $\begin{array}{l}\text { Reported co-morbidities } \\
\text { Hypertension and heart affections } \\
\text { Asthma and respiratory conditions } \\
\text { Infectious illnesses } \\
\text { Dermatological infections } \\
\text { Arthritis and musculoskeletal diseases } \\
\text { Gastrointestinal affections } \\
\text { Diabetes and metabolic disorders } \\
\text { Urogenital diseases } \\
\text { Visual disturbances }\end{array}$ & $\begin{array}{l}49(29.0) \\
9(5.3) \\
6(3.6) \\
5(3.0) \\
33(19.5) \\
18(10.7) \\
36(21.3) \\
17(10.1) \\
56(33.1)\end{array}$ & $\begin{array}{l}75(37.7) \\
11(5.5) \\
1(0.5) \\
3(1.5) \\
77(38.7) \\
49(24.6) \\
42(21.1) \\
11(5.5) \\
63(31.7)\end{array}$ & $\begin{array}{l}0.039 \\
0.932 \\
0.033 \\
0.641 \\
0.001 \\
0.001 \\
0.623 \\
0.102 \\
0.363\end{array}$ \\
\hline $\begin{array}{l}\text { Degree of dehydration } \\
\text { Severe dehydration } \\
\text { Mild dehydration }\end{array}$ & $\begin{array}{l}34(20.1) \\
135(79.9)\end{array}$ & $\begin{array}{l}51(25.6) \\
148(74.4)\end{array}$ & 0.308 \\
\hline $\begin{array}{l}\text { Hearing } \\
\text { Without problem } \\
\text { Hearing impairment }\end{array}$ & $\begin{array}{l}110(65.1) \\
59(34.9)\end{array}$ & $\begin{array}{l}138(69.3) \\
61(30.6)\end{array}$ & 0.503 \\
\hline $\begin{array}{l}\text { Dental and oral health } \\
\text { Good oral status } \\
\text { Partial and severe edentulism }\end{array}$ & $\begin{array}{l}21(12.4) \\
148(87.6)\end{array}$ & $\begin{array}{l}30(15.1) \\
169(84.9)\end{array}$ & 0.618 \\
\hline $\begin{array}{l}\text { Mini nutritional assessment-short form } \\
\text { Malnutrition: Zero to seven points } \\
\text { Risk of malnutrition: Eight to } 11 \text { points } \\
\text { Normal: } 12 \text { points or greater }\end{array}$ & $\begin{array}{l}25(14.8) \\
89(52.7) \\
55(32.5)\end{array}$ & $\begin{array}{l}30(15.1) \\
91(45.7) \\
78(39.2)\end{array}$ & 0.364 \\
\hline $\begin{array}{l}\text { Activities of daily living } \\
\text { Difficulty in everything } \\
\text { A moderate difficulty } \\
\text { No difficulties }\end{array}$ & $\begin{array}{l}30(17.8) \\
46(27.2) \\
93(55.0)\end{array}$ & $\begin{array}{l}25(12.6) \\
48(24.1) \\
126(63.3)\end{array}$ & 0.218 \\
\hline $\begin{array}{l}\text { Geriatric Depression scale (short form) } \\
\text { Severe depression: } 11-15 \\
\text { Mild to moderate depression: } 6-10 \\
\text { Normal: } 0-5\end{array}$ & $\begin{array}{l}18(10.7) \\
48(28.4) \\
103(60.9)\end{array}$ & $\begin{array}{l}39(19.6) \\
42(21.1) \\
118(59.3)\end{array}$ & 0.030 \\
\hline
\end{tabular}

\begin{tabular}{|c|c|c|c|c|c|c|}
\hline \multirow{2}{*}{$\begin{array}{l}\text { Variables and modalities } \\
\text { Marital status }\end{array}$} & \multirow{2}{*}{$\begin{array}{l}\beta \\
-1.359\end{array}$} & \multirow{2}{*}{$\begin{array}{l}\text { Wald } \\
19.157\end{array}$} & \multirow{2}{*}{$\begin{array}{l}p \\
0.000\end{array}$} & \multirow{2}{*}{$\begin{array}{l}\text { OR } \\
0.257\end{array}$} & \multicolumn{2}{|c|}{ 95\% Confidence interval } \\
\hline & & & & & 0.140 & 0.472 \\
\hline Education status & 0.006 & 0.001 & 0.981 & 1.006 & 0.604 & 1.675 \\
\hline Insurance health coverage & 0.709 & 2.547 & 0.111 & 2.033 & 0.851 & 4.857 \\
\hline Previous occupation levels & -1.419 & 36.162 & 0.000 & 0.242 & 0.152 & 0.384 \\
\hline Number of children & -0.918 & 8.057 & 0.005 & 0.399 & 0.212 & 0.753 \\
\hline Hypertension and heart diseases & 0.582 & 4.458 & 0.035 & 1.790 & 1.043 & 3.072 \\
\hline Infectious diseases & -1.770 & 2.189 & 0.139 & 0.170 & 0.016 & 1.777 \\
\hline Musculoskeletal diseases & 0.894 & 9.197 & 0.002 & 2.446 & 1.372 & 4.359 \\
\hline Gastrointestinal affections & 1.049 & 8.184 & 0.004 & 2.856 & 1.392 & 5.862 \\
\hline Urogenital affections & -0.628 & 1.538 & 0.215 & 0.534 & 0.198 & 1.440 \\
\hline Activities of daily living & 0.147 & 0.671 & 0.413 & 1.158 & 0.815 & 1.644 \\
\hline Geriatric depression scale (GDS-SF) & -0.211 & 1.312 & 0.252 & 0.809 & 0.564 & 1.162 \\
\hline
\end{tabular}


In Table 3, the multiple logistic regression model displayed that marital status 0.257 (95\% Cl: $0.140-0.472)$, previous occupation level 0.242 (95\% Cl: $0.152-0.384)$, number of children 0.399(95\% Cl: 0.212-0.753), musculoskeletal disorders 2.446 (95\% Cl: 1.372-4.359), and gastrointestinal diseases 2.856 (95\% Cl: 1.392-5.862) were relatively independent predictive variables associated with older women.

\section{Discussion}

This present cross-sectional is one of the few studies among elderly people in Morocco. Regarding the socio-economic status, older women were significantly more likely than men to have low previous occupational status (79.9\%) or to live in low-income families, to be widowed or single $(66.8 \%)$, to be illiterates $(78.9 \%)$ and to rely financially on their children (74.87\%). These findings have been corroborated by earlier studies conducted in low- and middle-income countries $(9,10)$. Hence, similar studies found that illiteracy was higher among women than men counterparts $(9,10)$. Given this trend, the gender gap in education might significantly decrease in the future for older people, as a result, both of the improvements in the general level of education and of an increase in enrolment of Moroccan girls. Moreover, earlier studies have shown that older women are more likely to live alone, single or widowed in developing countries $(5,11,12)$. In fact, these gender differences can be attributed to remarriage tendencies observed particularly among older men in developing countries. As a consequence, older women often refused to remarry, because they fear social pressure, public judgment, insults and even humiliation from the community (5).

In this study, interviewed women continue to come up an affective relationship with their children and even relatives. Building on numerous prior studies and reports, many elders lost their income and remain dependent financially and socially on their children and even relatives $(11,13)$. Moreover, other studies have also revealed that poor socio-economic status and illiteracy are the negative determinants associated with older women in developing countries $(9,14)$. In Morocco, the homemaker position of women could explain their poor socioeconomic status, their low outdoor physical activity and their financial dependence on their relatives.

In this investigation, the most elders suffered from multiple chronic diseases, functional disabilities and malnutrition with no significant difference between women and men, but considerably with a higher prevalence of depressive symptoms, gastrointestinal and musculoskeletal diseases in women, being the most disadvantaged. Similar findings displayed that elderly people are mostly suffering from chronic conditions, functional impairments and depressive symptoms $(1,14,15)$. In addition, the musculoskeletal, cardiovascular, gastrointestinal diseases, depression and dehydrations were strongly the most important co-morbidities appeared among older people. Besides, previous studies have shown the same results in Lebanon and the Middle East as a whole $(13,16)$. Furthermore, earlier studies have described that older women have significantly higher prevalence of diabetes, hypertension, arthritis, osteoporosis, migraine, autoimmune and musculoskeletal diseases than men counterparts $(1,13,16-19)$. In analogous studies, the higher prevalence of musculoskeletal disorders in the elderly women can be explained by their painful household activities and their higher prevalence of overweight and obesity $(20,21)$ Likewise, a relationship has been observed between musculoskeletal diseases and negative determinants of health, such as overweight, low education, poor health, and sedentary lifestyle $(21,22)$. In contrast, empirical research has shown that older women, who tend to have multiple chronic conditions rather than fatal, have a longer life expectancy than their male counterparts (1).

Furthermore, the results from the binary logistic regression analysis demonstrated that gastrointestinal diseases were significantly recognized in elderly women and were not intrinsically different from those which occur in men. Besides, other studies have found that women are more likely to suffer from constipation, bloating, swollen belly, tight clothing, irritable bowel, rectocele and asthenia $(23,24)$. In addition, Rectocele syndrome was often due to advanced age, multiparty, vaginal delivery, pelvic surgery and other conditions which are increasing intra-abdominal pressure such as obesity and constipation in elderly women (25).

Regarding depressive symptoms recognized as a public health problem commonly identified in the elderly, our study found that $19.6 \%$ of older women had significantly some degree of severe depression. This burden is often combined with poor self-rated health and low socio-economic status which can negatively affect successful aging in Morocco. Similarly, empirical studies have shown older women are considerably more likely to develop severe depression than men counterparts (26-29). As a result, the women psychological traumatism are possibly related to complex interactions including, poor socio-economic status, low education level, reduced daily activity, poor health state, neurobiological changes and stressful life events $(13,15)$.

\section{Study Limitations}

Our study limitations included that further investigations among the elderly people should be conducted in other Moroccan regions in order to provide additional information. In addition, a high-quality of dialogue between all participants will be recommended for a better management of successful aging in Morocco. 


\section{Conclusion}

Chronic diseases and depressive symptoms were common concerns in elderly people. As a result, we suggest that special attention and comprehensive clinical evaluations should be carried out, particularly in elderly women suffering from depressive symptoms and multiple chronic diseases. Therefore, our findings have demonstrated the need for an integrated national framework to analyse the impact of socio-economic and demographic factors on women's health status as a basis for developing policies and interventions in Morocco.

\section{Acknowledgements}

The authors thank the participants of this study. Special thanks go to Mr. Rahhou Lhoussin for his invaluable help in writing this article.

\section{Ethics}

Ethics Committee Approval: This study was conducted with the approval of the Ethic of the health authorities in the Region of Marrakech-Safi.

Informed Consent: Informed consent was obtained.

Peer-review: Internally peer-reviewed.

\section{Authorship Contributions}

Concept: A.B., A.H., M.C., Design: A.B., A.H., M.C., Data Collection or Processing: A.B., A.H., M.C., Analysis or Interpretation: A.B. A.H., R.A.A., E.K., M.C., Literature Search: A.B., A.H., R.A.A., M.C., Writing: A.B., A.H., M.C.

Conflict of Interest: Authors have declared no conflicts of interest.

Financial Disclosure: The authors declared that this study received no financial support.

\section{References}

1. Adjei NK, Brand T, Zeeb H. Gender inequality in self-reported health among the elderly in contemporary welfare countries: a cross-country analysis of time use activities, socioeconomic positions and family characteristics. PLoS One 2017;12:e0184676.

2. Noroozian M. The elderly population in Iran: an ever growing concern in the health system. Iran J Psychiatry Behav Sci 2012;6:1-6.

3. Barreto SM, Giatti L, Kalache A. Gender inequalities in health among older Brazilian adults. Pan Am. J. Public Health 2004;16:110-117.

4. Vlassoff, $\mathrm{C}$. Gender differences in determinants and consequences of health and illness. J Health Popul Nutr 2007;25:47-61.

5. Osmani N, Matlabi H, Rezaei M. Barriers to Remarriage Among Older People: Viewpoints of Widows and Widowers. J Divorce Remarriage 2018;59:51-68.

6. Soysal P, Veronese N, Arik F, Kalan U, Smith L, Isik AT. Mini Nutritional Assessment Scale-Short Form can be useful for frailty screening in older adults. Clin Interv Aging 2019;14:693-699.
7. Elsawy B, Higgins KE. The geriatric assessment. Am Fam Physician 2011;83:48-56.

8. Chaaya M, Sibai AM., El Roueiheb Z, Chemaitelly H, Chahine LM, Al-Amin $H$, Mahfoud Z. Validation of the Arabic version of the short Geriatric Depression Scale (GDS-15). Int Psychogeriatr 2008;20:571-581.

9. Yount KM, Sibai AM. Demography of aging in the Arab countries. International Handbook of Population Aging. Volume 1. Edited by: Uhlenberg P. Dordrecht: Springer Netherlands, 2009 p 277-315.

10. Al Hazzouri AZ, Sibai AM, Chaaya M, Mahfoud Z, Yount KM. Gender differences in physical disability among older adults in underprivileged communities in Lebanon. J Aging Health 2011;23:367-382.

11. Doumit JH, Ramzi NN, Dimitri RH. Nutritional and health status among nursing home residents in Lebanon: comparison across gender in a national cross sectional study. BMC Public Health 2014;14:629.

12. Endo Y, Aharonoff GB, Zuckerman JD, Egol KA, Koval KJ. Gender differences in patients with hip fracture: a greater risk of morbidity and mortality in men. J Orthop Trauma 2005;19:365-366.

13. Hajjar RR, Atli T, Al-Mandhari Z, Oudrhiri M, Balducci L, Silbermann M. Prevalence of aging population in the Middle East and its implications on cancer incidence and care. Ann Oncol 2013; 24(Suppl 7):vii11-vii24.

14. Khaje-Bishak Y, Payahoo L, Pourghasem B, Jafarabadi MA. Assessing the quality of life in elderly people and related factors in tabriz, iran. J Caring Sci $2014 ; 3: 257-263$

15. Roberts KC, Rao DP, Bennett TL, Loukine L, Jayaraman GC. Prevalence and patterns of chronic disease multimorbidity and associated determinants in Canada. Health Promot Chronic Dis Prev Can 2015;35:87-94.

16. Boulos C, Salameh P, Barberger-Gateau P. The AMEL study, a cross sectional population-based survey on aging and malnutrition in 1200 elderly Lebanese living in rural settings: protocol and sample characteristics. BMC Public Health 2013;13:573.

17. Senanayake P. Women and reproductive health in a graying world. Int J Gynaecol Obstet 2000;70:59-67.

18. Oksuzyan A, Juel K, Vaupel JW, Christensen K. Men: good health and high mortality. Sex differences in health and aging. Aging Clin Exp Res 2008;20:91-102.

19. Halilaj E, Moore DC, Laidlaw DH, Got CJ, Weiss APC, Ladd AL, Crisco JJ. The morphology of the thumb carpometacarpal joint does not differ between men and women, but changes with aging and early osteoarthritis. J Biomech 2014;47:2709-2714.

20. Sharma D, Mazta SR, Parashar A. Morbidity pattern and health-seeking behavior of aged population residing in Shimla hills of north India: A crosssectional study. J Family Med Prim Care 2013;2:188-193.

21. Andorsen OF, Ahmed LA, Emaus N, Klouman E. High prevalence of chronic musculoskeletal complaints among women in a Norwegian general population: the Tromsø study. BMC Res Notes 2014;7:506.

22. Buskila D, Abramov G, Biton A, Neumann L. The prevalence of pain complaints in a general population in Israel and its implications for utilization of health services. J Rheumatol 2000;27:1521-1525.

23. Hungin APS, Chang L, Locke GR, Dennis EH, Barghout V. Irritable bowel syndrome in the United States: prevalence, symptom patterns and impact. Aliment Pharmacol Ther 2005;21:1365-1375. 
24. Reginelli A, Pezzullo MG, Scaglione M, Scialpi M, Brunese L, Grassi R. Gastrointestinal disorders in elderly patients. Radiol Clin North Am 2008;46:755-771.

25. Mustain WC. Functional disorders: rectocele. Clin Colon Rect Surg 2017;30:63-75.

26. Girgus JS, Yang K, Ferri CV. The Gender Difference in Depression: Are Elderly Women at Greater Risk for Depression Than Elderly Men? Geriatric $2017 ; 2: 35$.
27. Kessler RC. Epidemiology of women and depression. J Affect Disord 2003;74:5-13.

28. Nolen-Hoeksema S. Gender differences in depression. Curr Dir Psychol Sci 2001;10:173-176.

29. Chan D, Kwok A, Leung J, Yuen K, Choy D, Lueng PC. Association between life events and change in depressive symptoms in Hong Kong Chinese elderly. J Affect Disord 2012;136:963-970. 